\title{
A causa coletiva: políticas públicas culturais para o cenário das redes sob a perspectiva da ecologia digital (a experiência brasileira)
}

* Mestra em Bens Culturais e Projetos Sociais pela Fundação Getúlio Vargas/ Centro de Pesquisa e Documentação de História Contemporânea do Brasil (FGV/CPDOC); autora do livro Jangada Digital, cuja versão integral está disponível, sob licença Creative Commons, no site Overmundo. Desde 2003, está à frente da política de patrocínios culturais da Petrobrás.
Eliane Costa*

\section{RESUMO}

Focalizando as políticas do Ministério da Cultura no período 2003-2010, e, em particular, a iniciativa relacionada à instalação de estúdios digitais de produção audiovisual conectados à internet nos Pontos de Cultura, este trabalho analisa a contribuição de políticas públicas para a promoção de diversidade cultural na rede, a ampliação do acesso aos bens e serviços culturais e ao conhecimento, o exercício dos direitos culturais, as interseções entre culturas locais e globais, bem como para o fortalecimento das possibilidades de compartilhamento e diálogo intercultural livre. Partindo do olhar ambientalista sobre o ciberespaço sugerido por James Boyle, o artigo ressalta a singularidade da experiência brasileira no período analisado, quando os fundamentos da ecologia digital ultrapassaram a esfera da militância civil, chegando às políticas públicas.

\section{PALAVRAS-CHAVE}

Cultura digital. Ecologia digital. Pontos de Cultura. COMmons. Políticas públicas. 
INTRODUÇÃO

Este artigo ${ }^{1}$ trata do contexto das redes e tecnologias digitais, tomado como campo de políticas públicas culturais, sob a perspectiva da ecologia digital. Trata, portanto, da questão do desenvolvimento sustentável no âmbito do ciberespaço. Uma abordagem ecológica desse ambiente, aqui entendido como um ecossistema, coloca em evidência o valor do uso público da informação e do conhecimento, para além de seu valor de uso comercial.

Essa temática foi tratada inicialmente, em 1997, pelo professor americano James Boyle, no artigo A Politics of Intellectual Property: Environmentalism for the Net?, ${ }^{2}$ no qual analisa a possibilidade de um olhar ambientalista sobre a rede. De acordo com o autor, assim como o esgotamento dos recursos naturais pode destruir a biosfera, a superproteção da propriedade intelectual pode fazer o mesmo com a ciberesfera.

Como contraponto, Boyle ressalta a necessidade de reconhecimento de espaços públicos no ambiente digital que possam incentivar o acesso ao conhecimento e à cultura, a liberdade de expressão, a criatividade e a inovação científica. Esses espaços traduzem a idéia de um coletivo de bens comuns digitais (digital commons ou, simplesmente, commons), de acesso público, livres para compartilhamento e para a produção de novas obras deles derivadas, desde que o caráter de bem comum seja nelas perpetuado, gerando, assim, novos commons.

A respeito dessa concepção, Lawrence Lessig escreve, em 2001, o livro The Future of Ideas: the Fate of the Commons in a Connected World. ${ }^{3}$ Dois anos depois, o pesquisador e militante francês Philippe Aigrain faz, no artigo Pour une coalition des biens communs, ${ }^{4}$ um chamamento aos defensores dos bens comuns de toda natureza: os informacionais, aqui tratados (envolvendo os movimentos relacionados ao software livre, mídias colaborativas, ciência aberta e cultura livre); os físicos (como a água, o ar, o clima) e os bens público-sociais, como educação e saúde. O autor aprofunda essa questão em dois livros: Cause commune: l'information entre bien commun et propriété

1 Versões deste trabalho foram apresentadas, em maio de 2011 no evento Communication, écologie et marché (USP/ECA e Sorbonne/CEAQ), e, em setembro do mesmo ano, no II Seminário Internacional de Políticas Culturais (Fundação Casa de Rui Barbosa).

2 Disponível em: http://scholarship.law.duke.edu/faculty_scholarship/165/. Acesso em: 01/09/2011.

3 Disponivel em: http://www.lessig.org/blog/2008/01/the_future_of_ideas_is_now_ fre_1.html. Acesso em: 05/09/2011.

4 Disponível em: http://paigrain.debatpublic.net/docs/bienscommuns.pdf. Acesso em: 01/09/2011. 
(2005), ${ }^{5}$ e Internet et création (2008). ${ }^{6}$ Nesse último, Aigrain analisa a emergência de modelos alternativos de remuneração dos criadores diante dos novos paradigmas da cibercultura. A versão eletrônica de todos esses trabalhos, não por acaso, está disponível para download na rede, sob uma licença Creative Commons.

Sob o ângulo das políticas públicas, este artigo aborda o cenário das redes e das novas tecnologias digitais de informação e comunicação (TIC), dando centralidade não à ótica tecnológica, ligada à infraestrutura desse contexto, mas, sobretudo, à ótica cultural, relacionada aos novos paradigmas de produção, circulação e consumo cultural que caracterizam a cibercultura. Busca-se evidenciar, por exemplo, a contribuição das políticas públicas para a promoção de diversidade cultural na rede, a ampliação do acesso aos bens e serviços culturais e ao conhecimento, o exercício dos direitos culturais, as interseções entre culturas locais e globais, bem como a gestão pública participativa no setor e o fortalecimento das possibilidades de compartilhamento, cooperação e diálogo intercultural livre. Mais precisamente, este trabalho aborda as políticas públicas desenvolvidas para esse cenário pelo Ministério da Cultura (MinC), a partir da gestão do músico e compositor Gilberto Gil, que teve início com o governo de Luiz Inácio Lula da Silva.

\section{Estúdios digitais nos PONTOS de Cultura}

Uma das mais importantes iniciativas do MinC no período analisado foi a criação dos Pontos de Cultura, no âmbito do Programa Cultura Viva, lançado em julho de 2004. Instalados em comunidades em situação de vulnerabilidade social por todo o País, em pequenos municípios ou na periferia das grandes cidades, cada Ponto de Cultura é dotado de um estúdio digital de produção audiovisual conectado à internet.

É justamente a presença desses estúdios que reforça a singularidade da iniciativa, já que eles possibilitam tanto a produção de conteúdos culturais digitais - como vídeos, fotografias, músicas, documentários, blogs e sites, programas para rádios e televisões comunitárias -, como também a difusão dessas produções pela internet. Trata-se, assim, da expressão cultural de uma comunidade, percebida e registrada por ela mesma, em meio digital: pronta, portanto, para difusão ilimitada pela rede.

5 Disponivel em: http://paigrain.debatpublic.net/?page_id=160/.

Acesso em: 09/09/2011.

6 Disponível em: http://www.ilv-edition.com/pdf_ebook_gratuit/internet_et_creation.pdf. Acesso em:12/09/2011. 
Em seu discurso de posse, em janeiro de 2003, citando o shiatsu do-in (a técnica oriental de massagem que se baseia na pressão dos dedos sobre pontos onde a energia vital do corpo está represada), o novo ministro da cultura Gilberto Gil prometera fazer um “do-in antropológico” no corpo cultural do País, massageando pontos vitais momentaneamente adormecidos ou esquecidos. Essa foi, exatamente, a missão que o $\mathrm{MinC}^{7}$ definiu para os Pontos de Cultura, lançados dezoito meses depois "desesconder o Brasil, reconhecer e reverenciar a cultura viva de seu povo" .

No primeiro Encontro Nacional de Pontos de Cultura, realizado em São Paulo, em 2006, o então ministro Gil declara: ${ }^{8}$

Este programa revela o quanto do que se chama 'realidade' é apenas uma versão

da história. Há manifestações de resistências, beleza guerreira e afirmação de respeito que não saem nos jornais, revistas, rádios ou TVs. Estes Pontos de Cultura são realidades que agora se mostram e se cruzam com a força autêntica da cultura

feita por quem a vive como esta teia.

A mencionada teia tem nos estúdios digitais, ligados à internet, a sua semente e infraestrutura, sendo dinamizada pelos Pontões Digitais, criados pelo MinC, em 2007, com esse objetivo.

Os Pontos de Cultura são escolhidos por edital público, entre iniciativas já desenvolvidas por organizações da sociedade civil há pelo menos dois anos, em localidades onde a oferta de serviços públicos e equipamentos culturais se mostra precária ou insuficiente. A proposta inverte, dessa forma, a lógica de atuação do Estado: não é o governo que leva uma ação às comunidades; são elas que definem as práticas que desejam fortalecer, a partir do reconhecimento e do apoio do governo.

O Ponto de Cultura não é nem um serviço, nem um equipamento cultural criado pelo Estado: ele representa o apoio deste a uma iniciativa que já se desenvolve, por exemplo no interior de uma favela, numa aldeia indígena ou numa comunidade quilombola. Seu foco não é a carência, mas a potência e a capacidade de ação dos indivíduos e dos grupos, como destaca Célio Turino (2009), ex-Secretário de Cidadania Cultural do MinC. O Ponto não é um evento, mas o processo. Exige, portanto, para sua maturação, tempo e atenção para a especificidade de cada experiência.

Com essa iniciativa, o Ministério da Cultura passa a ressaltar o potencial

Disponivel em:. http://www1.folha.uol.com.br/folha/brasil/ult96u44344.shtml. Acesso em 21/09/2011.

8 Trecho de discurso de Gilberto Gil citado por ANDRIES (2010). 
de transformação e as oportunidades culturais suscitadas pelo cenário das redes, representados pelas novas possibilidades de expressão e ressonância, pela emergência de formas ampliadas de compartilhamento, articulação, colaboração e de acesso à informação e ao conhecimento. Tendo como conceitos fundadores autonomia, empoderamento, protagonismo e gestão em rede, o Programa incentiva a apropriação tecnológica sob a perspectiva de transformação e promove a experiência da gestão pública participativa no setor cultural.

Além do apoio financeiro ( $R$ \$180 mil, pagos diretamente aos Pontos ao longo de três anos, para que estes realizem as atividades propostas no projeto apresentado ao MinC), as iniciativas selecionadas recebem a chancela institucional do Ministério, o que é fundamental para muitos deles em seu relacionamento com as comunidades onde estão inseridos e com os poderes públicos locais.

O conjunto dos Pontos é muito heterogêneo: para alguns, o aporte financeiro, embora pequeno (cerca de $\mathrm{R} \$ 5 \mathrm{mil} / \mathrm{mês}$ ), é importante; para outros, é absolutamente vital. Nessa heterogeneidade - de porte, de tempo de existência, de públicos envolvidos, de propostas, de desafios inerentes a cada comunidade - reside uma das riquezas do programa.

Em 2008, a seleção de novos Pontos de Cultura passa a ser realizada em parceria com os estados e/ou municípios, tendo sido firmados, até abril de 2010, convênios do MinC com 24 estados e 16 municípios no País. A descentralização desencadeia novas redes e maior compartilhamento dos conceitos, objetivos e recursos do Programa, que atua, assim, na perspectiva da consolidação de um Sistema Nacional de Cultura, que institucionalize a cooperação entre a União, os estados e os municípios na formulação, fomento e execução de políticas culturais de forma compartilhada e pactuada com a sociedade civil.

Toda essa rede já é dinamizada pela conexão dos Pontos de Cultura à internet, que se configura como natural infraestrutura e veículo para a ampliação de ações de formação, bem como para a implantação de necessárias melhorias ou correção de rumos na gestão do Programa. Nesse caso encontra-se, por exemplo, a necessidade de aprimoramento dos mecanismos do Estado para a gestão de iniciativas nesse formato, dificuldade que vem sendo apontada pelo próprio MinC desde a implementação do Programa. O fortalecimento da rede é, portanto, vital para a perspectiva de processo, que é inerente ao contexto aqui tratado. 
De acordo com o pesquisador da Universidade Federal da Bahia (UFBA) Andre Lemos (2003), a cibercultura é regida por três princípios fundamentais. O primeiro diz respeito à liberação do pólo de emissão: o consumidor de informação na rede é, igualmente, um produtor de informação, o que favorece a emergência de novos protagonistas e criadores, novas vozes e discursos, em oposição à edição hegemônica de mensagens que caracterizou a mídia de massa do século XX. O segundo se refere ao princípio da conexão em rede, que provê a infraestrutura tecnológica do ambiente e cria novas perspectivas para a difusão de expressões culturais que, frequentemente, mostram-se pouco sedutoras ao mercado e às mídias tradicionais. E o terceiro, que se relaciona à substancial reconfiguração de formatos midiáticos e de práticas sociais.

Fala-se aqui, portanto, de um contexto que, claramente, transcende a abordagem meramente tecnológica e remete a novas práticas, valores e possibilidades. Pierre Lévy (1999, p. 247) já previa, há dez anos, que, “longe de ser uma subcultura dos fanáticos pela rede, a cibercultura expressa uma mutação fundamental da própria essência da cultura".

É interessante ressaltar que a política pública representada pelos Pontos de Cultura trouxe, pelo menos, duas inflexões importantes:

I. A primeira é que, até então, o contexto das redes e tecnologias digitais estivera restrito às esferas técnicas do governo, no âmbito dos órgãos de ciência, tecnologia e telecomunicações. Prova disso é a composição do Comitê Gestor da Internet, criado em 1995. O Comitê foi revisto em 2003, sem, no entanto, jamais ter chegado a incluir um representante do setor cultural entre seus membros. Na gestão Gil, o Ministério da Cultura não somente ampliou suas atribuições, mas, sobretudo, expandiu sua concepção de cultura, absorvendo o contexto digital como um campo de políticas culturais. Os Pontos de Cultura, com seus estúdios digitais, constituem, justamente, a primeira política pública cultural brasileira voltada a esse contexto.

II. A segunda é que, com a proposta dos Pontos de Cultura, o Ministério amplia, também, a concepção de inclusão digital, passando a tomar o acesso ao computador e à internet não mais como linha de chegada, mas como o ponto de partida para novas práticas e possibilidades. Ultrapassa, assim, a ótica focada no hardware, incorporando a reflexão sobre os usos da tecnologia no domínio da cultura, bem como a perspectiva da autonomia do usuário e o fortalecimento de uma cultura de redes. 0 Ministério passa a chamar essa abordagem de cultura digital. 
A nova concepção trazida por Gilberto Gil ao Ministério da Cultura evidenciava a essência tropicalista do artista. 0 ministro fora, nos anos 1960, um dos ícones do Tropicalismo, movimento de ruptura que sacudira o ambiente da música popular e da cultura brasileira, ao assimilar criativamente linguagens da cultura jovem mundial, como 0 rock, as roupas psicodélicas e as guitarras elétricas, neles imprimindo marca própria, original e tropical. A proposta tinha raízes no Movimento Antropofágico, que, na década de 1920, havia reunido expoentes do Modernismo brasileiro em torno da proposta de repensar a questão da dependência cultural no Brasil. Em 1928, Oswald de Andrade lançara a base conceitual do movimento - o Manifesto Antropofágico - que, em linguagem metafórica e poética, propunha deglutir, “antropofagicamente”, as inovações estéticas que vinham de fora, digeri-las na cultura popular e então regurgitá-las.

Na condição de ministro, Gil associava claramente a concepção de cultura digital, trazida por sua gestão, à “regurgitação antropofágica” dos modernistas. Nas combinações e remixagens ${ }^{9}$ do mundo digital, identificava a concretização das idéias tropicalistas: "São tempos irremediavelmente tropicalistas, porque o Tropicalismo era a capacidade de operar com fragmentos, o que hoje é a linguagem corrente". ${ }^{10}$ Gil identifica sua própria decisão de aceitar o Ministério como o desenvolvimento de um sentimento tropicalista: "11 "Tudo o que enfatiza o sentido democrático da convivência dos diversos modos de manifestação cultural e tem o impulso de aventura é tropicalista".

A proposta dos Pontos de Cultura está em sintonia com as recomendações da Convenção sobre a Proteção e Promoção da Diversidade das Expressões Culturais, adotada em 2005, por ocasião da 33a Seção da Conferência Geral da UNESCO. A propósito do documento ${ }^{12}$, já ratificado por 116 países, a instituição declara que:

a cultura não pode mais ser considerada como um sub-produto do desenvolvimento,

e sim como recurso fundamental do

desenvolvimento sustentável.

9 Os termos remixagem ou remix identificam a produção de novas obras a partir de colagens e combinações de obras já existentes.

10 Disponível em: http://www.observatoriodaimprensa.com.br/artigos.asp?cod=485ASP014. Acesso em: 01/10/2011

11 Entrevista de Gilberto Gil para o site Tropicália. Disponível em: www.tropicalia.com.br). Acesso em: 01/10/2011.

12 Disponível em: http://unesdoc.unesco.org/images/0014/001429/142919f.pdf. Acesso em: 05/10/2011. 
Ao incentivar a produção de conteúdos culturais diversificados, e em formato digital, os Pontos de Cultura contribuem para a promoção da diversidade lingüística e cultural no ciberespaço, como recomenda a mesma Convenção ${ }^{13}$ que, sobre esse ponto, lança um alerta:

\begin{abstract}
“Os processos de globalização, facilitados pela rápida evolução das tecnologias de comunicação e informação, apesar de proporcionarem condições inéditas para que se intensifique a interação entre culturas, constituem também um desafio para a diversidade cultural, especialmente no que diz respeito aos riscos de desequilíbrios
\end{abstract} entre países ricos e pobres".

Do ponto de vista estritamente tecnológico, não existe hoje obstáculo algum à universalização e ao compartilhamento do conhecimento. Essa utopia, no entanto, é combatida por interesses econômicos e geopolíticos poderosos, configurando-se aí, precisamente, o campo de ação da ecologia digital.

Como aponta Canclini (2005), a internet e as tecnologias digitais se propagam pelo planeta de maneira rápida, porém extremamente desigual, criando novas diferenças e desigualdades. 0 site Internet World Stats, ${ }^{14}$ que monitora a utilização da internet ao redor do mundo, aponta que, em 31 de dezembro de 2010, dois bilhões de pessoas tinham acesso à rede, número que, no entanto, representa apenas $29,6 \%$ da humanidade.

A esses dados, Manuel Castells (2003) acrescenta que a verdadeira divisão digital (ou fratura digital) não pode ser medida simplesmente pela quantificação dos internautas, mas pelas consequências, tanto da conexão, quanto da falta de conexão. $O$ autor ressalta que a centralidade da internet em grande parte das áreas da atividade social, econômica e política corresponde à marginalidade para mais de $70 \%$ dos habitantes do planeta, que a ela não têm acesso, ou têm acesso limitado por algum motivo.

No já mencionado site Internet World Stats, pode-se observar que a taxa de penetração da internet na América do Norte é de 78,8\%, e, na Europa, de 58,4\%, enquanto, na Africa, é de apenas 11,4\%. Essa disparidade é, claramente, um obstáculo ao desenvolvimento das regiões mais afetadas, não como consequência da internet em si, mas da desigualdade que cerca as oportunidades de acesso ao que ela pode representar.

Por outro lado, como acrescenta Castells (2003), a divisão digital não se relaciona apenas com a possibilidade ou não de acesso à infraestrutura tecnológica, mas envolve também a qualidade desse uso e o contexto em

13 Disponível em : http://unesdoc.unesco.org/images/0014/001429/142919f.pdf. Acesso em: 05/10/2011.

14 Disponível em : http://www.internetworldstats.com/. Acessado em 07/10/2011. 
que se dá sua apropriação. 0 autor registra que a exclusão digital pode se dar por diferentes mecanismos, como dificuldades econômicas, políticas ou institucionais de acesso à rede, bem como por insuficiência de recursos educacionais e culturais que permitam seu uso autônomo.

Outro aspecto da divisão digital também apontado por Castells (2003) é a desvantagem na produção do conteúdo comunicado através das redes. No contexto da globalização, o autor chama a atenção para o que poderia ser uma troca intensiva de bens simbólicos entre os diferentes países, que, no entanto, muitas vezes se limita a um fluxo de mão única que ameaça a criatividade e a viabilidade econômica dos países não hegemônicos e 0 próprio ideal de um mundo polifônico.

Nos últimos anos, diversos compromissos foram firmados, na esfera internacional, no sentido de enfrentar os diferentes desequilíbrios relacionados ao quadro de divisão digital global. Em 2000, na Cúpula do Milênio ${ }^{15}$ promovida pela ONU, 191 países, incluindo o Brasil, se comprometeram com oito metas, dentre as quais a de promover uma parceria mundial pelo desenvolvimento.

Em seguida, a Cúpula Mundial da Sociedade de Informação, também promovida pela ONU (em duas etapas: em Genebra, em 2003, e em Túnis, em 2005) reafirmou sua determinação pela construção de uma sociedade de informação que leve em conta a dimensão humana, solidária, e que privilegie o desenvolvimento, de forma a que todos possam, em qualquer parte do mundo, criar, acessar, utilizar e compartilhar a informação e o conhecimento. ${ }^{16}$

Em 2004, o Relatório de Desenvolvimento Humano, ${ }^{17}$ divulgado pelo Programa das Nações Unidas para o Desenvolvimento (PNUD), colocou, pela primeira vez, o tema da liberdade cultural em pé de igualdade com as questões da democracia e das oportunidades econômicas. 0 documento ressalta que a liberdade de escolher uma identidade cultural, e de exercê-la sem discriminações ou desvantagens, é vital para o desenvolvimento humano.

No ano anterior, os ministros da cultura de 16 países haviam solicitado 0 respaldo dessa organização para que pudessem exercer, de forma autônoma,

15 Disponível em: http://bvsms.saude.gov.br/bvs/publicacoes/declaracao_milenio_nacoes_unidas.pdf. Acesso em: 29/09/2011.

16 Disponivel em: http://www.itu.int/wsis/documents/doc_multi.asp?id=2266\%7C0. Acesso em : 18/10/2011.

${ }_{17}$ Disponível em: http://hdr.undp.org/en/media/hdr04_fr_complete.pdf. Acesso em: 19/10/2011. 
seu direito de criar ou preservar suas próprias políticas culturais nacionais relativas à produção e à circulação de conteúdos culturais. Essa demanda resultou, em 2005, na elaboração da já citada Convenção sobre a Proteção e Promoção da Diversidade das Expressões Culturais.

Ainda em 2004, a Organização Mundial da Propriedade Intelectual (OMPI) considerou, também pela primeira vez, as dimensões “desenvolvimento" e “acesso ao conhecimento" como partes integrantes de seu trabalho. Essa mudança resultou de um posicionamento pioneiro e decisivo do Brasil e da Argentina, que conseguiram a incorporação dessa nova ótica à Agenda do Desenvolvimento da organização, tornando a propriedade intelectual uma dimensão favorável não apenas aos países desenvolvidos.

O Compromisso de Túnis, ${ }^{18}$ firmado em 2005 por todos os países participantes da Cúpula Mundial da Sociedade de Informação, reconheceu também a liberdade de expressão e a livre circulação das informações, das idéias e do saber como essenciais à sociedade de informação e ao desenvolvimento.

Apesar de todos esses compromissos, o estabelecimento de uma verdadeira cultura de compartilhamento, cooperação e trocas abertas - atributos indissociáveis do contexto das redes - continua marcado por impasses e discussões complexas na maioria dos países. A criatividade, a inovação e a utopia da universalização - não só do acesso ao conhecimento, mas também à sua produção -, tecnicamente viabilizadas pelo cenário das redes, continuam associadas à instabilidade, insegurança e exclusão.

De um lado, o direito universal de acesso à cultura; de outro, autores e os direitos relacionados às suas obras - legítimos, sem dúvida, embora, em alguns casos, superestimados ou definidos em um contexto tecnológico bastante diverso do atual. Ou ainda: de um lado, projetos informacionais cooperativos como a Wikipedia, ${ }^{19}$ o software livre, novas formas artísticas como a música hip-hop, o remix, a arte e a cultura livre; do outro, a ofensiva industrial, econômica e a política mundial contra a pirataria, que insiste em combater o compartilhamento de informação sem fins lucrativos entre indivíduos com os mesmos instrumentos jurídicos e de polícia utilizados contra a pirataria e o roubo de produtos físicos.

Os debates acima estão colocados de forma contundente no Brasil, onde,

18 Disponivel em : http://www.itu.int/wsis/documents/doc_multi.asp?id=2266\%7C0. Acesso em : 19/10/2011.

19 A enciclopédia de acesso livre na rede, cujos verbetes podem ser criados ou modificados por qualquer pessoa. 
durante a gestão de Gilberto Gil (e de seu sucessor, Juca Ferreira), o Ministério da Cultura elegeu a reforma dos direitos de autor e o debate sobre a cultura livre como duas de suas principais frentes, o que lhe trouxe, ao mesmo tempo, críticas severas e apoios apaixonados.

As maiores objeções foram colocadas pelos partidários do modelo préinternet e pré-popularização das tecnologias digitais, no qual a produção e a difusão de bens culturais exigiam caros processos industriais, o que “justificava”, de alguma forma, a privatização da expressão pública. Ao contrário, a cibercultura suscitou uma situação inteiramente distinta, na qual todo cidadão pode exercer, diretamente, sua liberdade de expressão pública.

Nas mais diversas estatísticas atuais, o Brasil vem sendo apontado como um país onde a apropriação das novas tecnologias de informação e comunicação se dá de maneira extremamente significativa. Hoje, em torno de 80 milhões de brasileiros (cerca de $41 \%$ da população do País) têm acesso à internet. ${ }^{20}$ Destes, $87 \%$ acessam a rede pelo menos uma vez por semana e $86 \%$ participam de redes sociais. ${ }^{21}$

Por outro lado, o acesso aos telefones celulares torna-se, cada vez mais, um parâmetro significativo de inclusão digital: hoje, há quase 5 bilhões de usuários de celulares no planeta, ${ }^{22}$ frente aos já mencionados 2 bilhões de internautas. No Brasil, há 212,6 milhões de celulares, para uma população de 193 milhões de pessoas, o que aponta para uma taxa de 110 aparelhos para cada 100 habitantes. ${ }^{23}$

Um fato que também chama a atenção no Brasil é a apropriação tecnológica pelas populações chamadas periféricas. Em cada favela brasileira proliferam as lan-houses, onde os moradores da comunidade têm acesso à rede, pagando barato. A maioria desses empreendimentos está instalada em espaços improvisados, acoplados a moradias ou ocupando pequenas “lojas” em ruelas, fora da economia formal. Um terço dos internautas brasileiros acessa a internet a partir de alguma das cerca de 100 mil lan-houses espalhadas por todo o País. ${ }^{24}$

Ações de inclusão digital de governos estaduais favorecem, também, o

20 Pesquisa F/Nazca - DataFolha, março de 2011

21 Ibope Nielsen Online, dezembro de 2010.

22 Dados da União Internacional de Telecomunicações, janeiro de 2011.

23 Dados do site da Presidência da República. Disponivel em: www.brasil.gov.br. Acesso em: 30/04/2011.

24 Ibope Nielsen Online, dezembro de 2010. 
acesso da população à rede. A favela Santa Marta, por exemplo, situada na zona sul do Rio de Janeiro e com 10 mil habitantes, foi a primeira do País onde a internet sem fio, em banda larga, foi implantada. Até o momento, o Programa inclui também a Cidade de Deus e a orla das praias de Copacabana, Leme, Ipanema e Leblon.

Ao mesmo tempo, surgem no Brasil iniciativas autônomas e inovadoras: redes e coletivos baseados na economia solidária e voltados à produção e escoamento alternativos de produtos culturais, para além dos grandes circuitos e centros, como o Fora do Eixo, movimento nascido em Cuiabá (MT) em 2005, com conexões iniciais em Uberlândia (MG), Rio Branco (AC) e Londrina (PR) e hoje presente em todos os estados brasileiros. Somente no ano passado, mais de cinco mil bandas circularam por meio das ações da rede Fora do Eixo.

Iniciativa bastante original é, também, o portal colaborativo "Viva Favela", ${ }^{25}$ já com dez anos de existência na internet. Promovido pela ONG Viva Rio, é atualizado por “correspondentes comunitários” de diferentes favelas do país. É focado na cultura dessas comunidades e nas estratégias adotadas por seus habitantes para superar as dificuldades quotidianas.

Do que falamos então? Falamos de milhões de novos criadores e protagonistas que se integraram ao tecido cultural brasileiro nos últimos anos, acessando a rede através de Pontos de Cultura, de lan-houses, de telecentros comunitários, de suas próprias casas, ou de oficinas empreendidas por projetos sócioculturais como "Nós do Morro", "Afroreggae", "Observatório das Favelas", "Central Única das Favelas”, dentre muitos outros. Trata-se de uma situação completamente nova, que não pode, absolutamente, deixar de ser levada em conta pelas políticas públicas culturais.

As prioridades do Ministério da Cultura, nos oito anos mencionados, guardaram sintonia com a atenção que, desde os primeiros meses, o governo Lula dedicou aos novos paradigmas da cibercultura, expressa, por exemplo, na orientação de adoção de software livre em todos os órgãos da administração pública federal. Essa diretriz foi defendida pelo governo, na ocasião, não como simples troca de produto, mas como a opção por um modelo de desenvolvimento que privilegia a soberania do país sobre as tecnologias que utiliza, ${ }^{26}$ bem como a inovação contínua e o valor do compartilhamento da

Disponpivel em: www.vivafavela.com.br. Acesso em 02/10/2011.

26 O movimento pelo software livre (Open Source) se baseia no compartilhamento do conhecimento tecnológico. Refere-se a programas de computador cujo código-fonte (a sequência de instruções 
inteligência, ícones da concepção do software livre.

A rejeição ao $\mathrm{ACTA}^{27}$ e a outros projetos de criminalização de internautas, bem como o processo de construção, iniciado em 2009, do primeiro marco regulatório para a internet no País (o Marco Civil, ainda em trâmite de aprovação no Congresso) e a proposta de revisão da Lei de Direitos Autorais (também inconclusa) são outros exemplos das escolhas governamentais nesse contexto, fundamentadas na garantia dos direitos de acesso à rede e ao conhecimento.

A concepção do Marco Civil da Internet brasileiro, fruto de um trabalho coletivo liderado pelo Ministério da Justiça e pelo Centro de Tecnologia e Sociedade da Fundação Getúlio Vargas-Rio, incluiu a realização de consulta pública pela rede e envolveu um aspecto bastante singular. Em lugar de adotar, nesse documento, como diversos outros países, a ótica da censura e do controle, com prejuízo aos direitos da vida privada e dos consumidores, o governo brasileiro adotou a direção contrária, compreendendo o acesso à rede como um direito civil, essencial ao exercício da cidadania, da liberdade de expressão e do acesso à informação.

O Plano Nacional de Cultura (PNC), ${ }^{28}$ assinado em dezembro de 2010, representou, também, a ratificação do apoio do governo à ampliação do acesso à cultura sob a ótica da ecologia digital. Em sua seção Estratégias $e$ Ações, o documento que instituiu o PNC recomenda

"incentivar e fomentar o desenvolvimento de produtos e conteúdos culturais intensivos em conhecimento e tecnologia, em especial sob regimes flexíveis de propriedade intelectual” (p.1).

que o compõe) é aberto e livre, isto é, pode ser conhecido, usado, analisado, copiado, melhorado e redistribuído sob as condições estipuladas em sua licença. Isso não costuma ocorrer nos programas comerciais, cujos direitos pertencem, em sua maioria, às grandes corporações de desenvolvimento de software. O exemplo mais conhecido de software livre é o GNU/Linux, que já recebeu, nos últimos 20 anos, contribuições e melhorias de milhares de pessoas em todo mundo, sendo cada vez mais difundido. O software livre não deve, no entanto, ser confundido com o software de distribuição gratuita (freeware), aquele que se pode "baixar" da internet e usar sem pagar, pois nesse último caso o código-fonte pode, ou não, ser aberto.

27 Acordo comercial anti-pirataria baseado na generalização de medidas repressivas.

28 Disponível em: http://www.planalto.gov.br/ccivil_03/_ato2007-2010/2010/lei/l12343.htm. Acesso em: 17/09/2011.

cadernoscenpec | São Paulo | v.1 | n.1 | p. 127-145 | dez. 2011 


\section{CONCLUSÕES}

As questões aqui tratadas são, certamente, bandeiras de ativismo civil em todos os países onde essas discussões têm estado em pauta, com o respaldo de organizações internacionais como a Free Software Foundation ${ }^{29}$ e a Electronic Frontier Foundation,,$^{30}$ bem como da La quadrature du Net, ${ }^{31}$ organização francesa de defesa dos direitos e liberdades dos cidadãos na rede. Essas organizações intervêm, principalmente, nos debates relacionados à liberdade de expressão e ao respeito da vida privada, aos direitos autorais e à regulação do setor de telecomunicações.

A originalidade da experiência brasileira, entretanto, está no fato de que, no período aqui analisado, as duas soluções mais inovadoras relacionadas à concepção dos commons e aos fundamentos da ecologia digital - o software livre e as licenças alternativas como a Creative Commons - ultrapassaram a esfera da militância civil e foram incorporadas no nível das políticas públicas.

No período aqui estudado, o Brasil mostrou uma original sinergia, no contexto digital, entre políticas de governo e demandas da sociedade civil, no que foi observado de perto pelos mais importantes especialistas e ciberativistas do mundo, como o próprio Lawrence Lessig, já mencionado neste trabalho, Richard Stallmann, fundador, em 1985, da Free Software Foundation, e John Perry Barlow, que, em 1990, criou a Electronic Frontier Foundation, organismo não-governamental sem fins lucrativos dedicado à defesa das liberdades na rede. Os três estiveram diversas vezes no Brasil nos últimos anos.

Por outro lado, quando se fala de políticas públicas, paira sempre o risco da descontinuidade e da frustração. Em seus trabalhos, Antonio Albino Canelas Rubim (2010) tem destacado a "instabilidade" como uma das "três tristes tradições" da trajetória da relação do Estado brasileiro com o campo cultural, lado a lado com a "ausência" e o "autoritarismo". Nesses primeiros meses de transição presidencial e de mudança na orientação no Ministério da Cultura, as "tristes tradições" parecem pairar sobre os avanços conquistados no âmbito das políticas públicas culturais.

Os commons e a perspectiva da ecologia digital foram "nocauteados" logo nas primeiras semanas de janeiro. A argumentação reduziu a discussão a uma tomada de posição entre ser contra ou a favor "dos autores", denotando falta

\footnotetext{
Disponível em: http://www.fsf.org/. Acesso em: 15/09/2011.

- Disponivel em: http://www.eff.org/. Acesso em: 08/10/2011.

${ }_{31}$ Disponivel em: http://www.laquadrature.net/fr. Acesso em: 02/10/2011.
} 
de compreensão, tanto dos princípios fundamentais da causa dos commons, quanto do papel das licenças flexíveis para a própria sustentabilidade legal da natureza e das prerrogativas de tais conteúdos.

Pautando-se, justamente, pelo direito que tem o autor de definir os usos que quer dar a sua obra - e sem ferir a Lei de Direitos Autorais (LDA) vigente -, mecanismos como a licença Creative Commons (CC), dentre outras análogas, voltadas para a flexibilização do modelo de copyright (em que, ao contrário, todos os direitos estão, a priori, reservados), constituem modelos alternativos de licenciamento por meio dos quais o criador pode deliberar sobre sua obra - diretamente e sem intermediários -, no que se refere a cópias, compartilhamento, uso educacional ou comercial, criação de obras derivadas ou qualquer combinação dessas possibilidades, desde que essas mesmas autorizações sejam preservadas nos trabalhos resultantes.

Esses modelos vêm sendo identificados coletivamente como copyleft, o que se traduz em algo como "alguns usos permitidos". Licenças como essas constituem, dessa maneira, uma forma de tornar livres - parcial ou integralmente, e de acordo com a vontade do autor - os usos sobre uma produção, artística, científica ou educativa, ou mesmo um software, requerendo que qualquer versão gerada a partir dela, seja, também, livre.

Contratos de licenciamento baseados nessa filosofia podem atuar no sentido da ampliação do acesso à cultura e ao conhecimento, bem como da descriminalização de práticas que são hoje corriqueiras, já que intrínsecas aos paradigmas da rede (embora ilegais, de acordo com a LDA vigente, erigida em um cenário tecnológico com possibilidades inteiramente aquém das atuais). Diante dessa assincronia, o copyleft busca criar uma alternativa que equilibre os interesses privado e público.

São esses mecanismos que, no âmbito dos marcos regulatórios vigentes, podem viabilizar a criação de espaços coletivos (commons) na esfera digital, mencionados no início deste artigo, que nutrem e se integram às novas dinâmicas do mundo digital e à perspectiva ambientalista sobre a rede, como propõem os já citados Boyle, Lessig e Aigrain, dentre outros.

Contra diversas expectativas, muitos dos avanços obtidos nos últimos anos, relacionados ao contexto aqui tratado, encontram-se em compasso de espera neste momento, o que é curioso quando se leva em conta o reconhecimento internacional da singularidade da experiência brasileira e, sobretudo, quando se constata a influência progressiva e irreversível dos novos paradigmas 
do cenário das redes sobre as três dimensões da cultura: a simbólica, a econômica e a cidadã.

Entretanto, no contexto de desigualdade e exclusão que marcam o cenário global, é absolutamente vital que a perspectiva da causa coletiva esteja presente na abordagem contemporânea dos desafios e oportunidades potencializados pela cibercultura. Não é demais registrar aqui o alerta colocado por Philippe Aigrain em seu texto Le partage est légitime:32

"quando as possibilidades de compartilhamento são cerceadas, as práticas culturais empobrecedoras derrotam as enriquecedoras [...]. A proibição de compartilhamento será vista, um dia, como um desconcertante obscurantismo".

32 Disponível em: http://paigrain.debatpublic.net/?p=1766. Acesso em: 11/09/2011. 


\section{The collective cause: cultural public policies for the internet scenario from the perspective of digital ecology (the brazilian experience)}

\section{ABSTRACT}

This article analyzes the contribution of public policies to promote cultural diversity on the internet, access to knowledge and cultural goods and services, exercise of cultural rights, and the intersection between local and global cultures, as well as their ability to empower the possibilities for sharing and free intercultural dialogue. In order to do so, the paper focuses on the policies developed by the Brazilian Ministry of Culture during the period of 2003-2010, particularly on measures related to the creation of digital studios - connected to the internet - for audiovisual production in "Pontos de Cultura." Based on an environmentalist conception of cyberspace built by James Boyle, the article stresses the singularity of the Brazilian experience in the period analyzed, when the basis of a digital ecology surpassed the field of civil activism, reaching into the field of public policy.

KEYWORDS

Digital culture. Digital ecology and environment. "Pontos de Cultura". Commons. Public policies 


\section{Referências}

AIGRAIN, Philippe. Internet \& Création. Paris : Editions InLibroVeritas, 2008.

Cause commune : l'information entre bien commun et propriété.

Paris : Ed. Fayard, 2005.

ANDRIES, Andre. Pontos de cultura, uma experiência de política pública participativa. Monografia (Trabalho de conclusão de curso em Democracia Participativa, República e Movimentos Sociais). Belo Horizonte : Faculdade de Filosofia e Ciências Humanas da UFMG, 2010.

BOYLE, James. A Politics of Intellectual Property : Environmentalism For the Net. Duke Law Journal,[S.I.], n. 47, 87-116. 1997.

BRASIL. Minsitério da Cultura. Portaria Interministerial número 147. Brasília, 31 de maio de 1995 . Disponível em: http://www.cgi.br/regulamentacao/ port147.htm

CANCLINI, Nestor Garcia. Diferentes, desiguais e desconectados. Rio de Janeiro: Ed. UFRJ, 2005.

CASTELLS, Manuel. A Galáxia da Internet: reflexões sobre a internet, os negócios e a sociedade. Rio de Janeiro: Jorge Zahar, 2003.

COSTA, Eliane. Jangada Digital: Gilberto Gil e as políticas públicas para a cultura das redes. Rio de Janeiro: Azougue; Aeroplano, 2011.

FERNANDES, Taiane. Políticas para a cultura digital. In: RUBIM, Antonio Albino Canelas (Org). Políticas culturais no governo Lula. Salvador: EDUFBA, 2010.

HALL, Stuart. A identidade cultural na pós-modernidade. Rio de Janeiro: DP\&A, 2006.

LEMOS, André. Cibercultura: alguns pontos para compreender a nossa época. In: LEMOS, A.; CUNHA, P. (Org.). Olhares sobre a Cibercultura. Porto Alegre: Sulina, 2003.

LEMOS, Ronaldo. Direito, tecnologia e cultura. Rio de Janeiro: Editora FGV, 2005.

LESSIG, Lawrence. Free culture. Penguin: [s.n.], 2004.

. The future of ideas: the fate of the commons in a connected world.

[S.I.]: Random House, 2001. 
LÉVY, Pierre. Cibercultura. São Paulo: Ed. 34, 1999. Inteligência coletiva: por uma antropologia do ciberespaço. Ed. Loyola, 1998.

MANOVICH, Lev. Software Culture (Software takes command). Milano: Edizioni Olivares, 2010. Para download no site do autor.

. The Language of the New Media. [S.I.]: MIT Press, 2001.

MINISTÉRIO DA CULTURA (MinC). Cultura em três dimensões: as políticas do Ministério da Cultura de 2003 a 2010. Brasília, DF: MinC, 2009.

RUBIM, Antonio Albino Canelas. Políticas culturais no governo Lula. In:

(Org). Políticas culturais no governo Lula. Salvador: EDUFBA, 2010.

SAVAZONI, Rodrigo; COHN, Sergio (Org.). Culturadigital.br. Rio de Janeiro: Azougue Editorial, 2009.

SILVEIRA, Sérgio Amadeu; KUNSCH, Dimas A. Ciberespaço: a luta pelo conhecimento. São Paulo: Salesiana, 2008.

- O conceito de commons na cibercultura. In: XXX CONGRESSO BRASILEIRO DE CIÊNCIAS DA COMUNICAÇÃO, [S.I. : s.n], 2007.

Software Livre: a luta pela liberdade do conhecimento. São Paulo: Fundação Perseu Abramo, 2004.

Exclusão Digital: a miséria na era da informação. São Paulo: Fundação Perseu Abramo, 2001.

TURINO, Célio. Ponto de Cultura: o Brasil de baixo para cima. São Paulo: Anita Garibaldi, 2009.

YÚDICE, George. A conveniência da cultura: usos da cultura na era global. Belo Horizonte: Ed. UFMG, 2004.

Recebido em: SETEMBRO de 2011

Aprovado em: OUTUBRO de 2011 